\title{
Feeding Appliance for an Infant with Cleft Palate: A Case Report
}

\author{
Hilal Ahmad Hela ${ }^{1}$, Shazana Nazir ${ }^{2}$, Mehvash Qazi ${ }^{3}$ \\ ${ }^{1,3}$ PG Student, ${ }^{2}$ Asst. Professor, Department of Prosthodontics, GDC Srinagar, Jammu and Kashmir \\ Corresponding Author: Shazana Nazir
}

\begin{abstract}
The cleft palate is a "congenital defect of the middle third of the face that occurs when an oronasal communication is present between the palate and the base of the nose. Single genes, chromosomal disorders or environmental factors may cause clefts. The other possible causes are hormonal imbalances, nutritional deficiencies, infections, radiation during pregnancy, alcohol or cigarette consumption, the ingestion of other teratogenic substances by the mother, and heredity. Immediate problems to be addressed in a new born with this defect would be to aid in suckling and swallowing other problems associated later would be difficulty in speech, altered appearance, many dental problems and psychological problems. Feeding plate (obturator) rehabilitates the oro-nasal gap and helps in feeding and in reduction of airway problems, frequent infections and regurgitations. This paper presents a case report of an infant with cleft palate (Veau II) in whom a feeding plate was delivered, with a simple impression method, which helped the infant feed and restores the proper weight required for cleft palate reconstructive surgery in future.
\end{abstract}

Keywords: Cleft Lip, Cleft Palate, Infant, Obturator

\section{INTRODUCTION}

Cleft can be defined as a congenital abnormal gap in the palate that may occur alone or in conjunction with lip and alveolus cleft. The zones affected by common orofacial clefts are as upper lip, alveolar ridge, hard palate, soft palate, nose and eyes ${ }^{1}$ Neonates born with cleft lip and palate have oronasal communication which diminishes the ability to create negative pressure necessary for suckling, thereby hampers feeding and consequently disturbs child's nutrition ${ }^{2}$ and Learning to live with a change in one's appearance due to injury or disease is very difficult. It is all the more difficult for children born with developmental defects and their parents to adjust. The management of orofacial clefts requires an impulsive treatment schedule and multi-disciplinatory approach which further puts enormous mental and physical stress not only for the parents of the involved child but also for the entire family ${ }^{3}$.

Worldwide incidence of Cleft lip and palate is 1 in 600 and prevalence is 6.64 per 10,000 whereas the prevalence of Cleft lip with or without Cleft palate is 9.92 per 10,000 and Cleft lip alone is 3.28 per 10,000 . In India estimated birth rate is found to be 24.5 million births per year, and prevalence of cleft cases within them is approximated between 27,000 and 33,000 per year. The ratio of CL in male to female is 2:1, whereas Cleft palate without Cleft lip is more common in females. This is due to 1 week later fusion of the palatine shelves in girls as compared with boys, resulting in higher occurrence of Cleft palate in girls ${ }^{4-7}$

CLP may or may not be associated with various syndromes such as PierreRobin sequence, Stickler's syndrome, Di George syndrome, Treacher Collins malformation, trisomy 13 and 18, Apert's syndrome, and Waardenburg's syndrome. ${ }^{8}$ 
The most common problem associated with cleft is related to swallowing thus a feeding appliance is a favorable option in such cases as it obturates the cleft area and creates a stable platform toward which the baby can press the nipple and extract milk ${ }^{2}$.

\section{CASE REPORT}

An infant of one and half month was reported to the Department of Prosthodontics Crown and bridge, with complaint of difficulty in sucking of milk and nasal regurgitation while feeding. The weight of the child at birth was $2.5 \mathrm{~kg}$, and it was observed that the weight did not increase due to inability to take oral feed. There was no family history except that the parents had a consanguineous marriage. On clinical examination it was found that cleft of hard and soft palate was present (Veau's class II; Fig. 1). For the managing the feeding problems, a feeding plate was planned, which can act as barrier between the nasal and oral cavity thus preventing nasal regurgitation.

\section{Steps in Fabrication of Feeding Plate}

Impression making in Cleft lip and palate patient is a crucial and a challenging procedure due to limitation of the size of infant's oral cavity, variation in anatomy, and lack of cooperation of the patient to respond to commands while impression making. In the literature, different types of impression materials such as low fusing compound, alginate, and elastomeric impression material have been recommended, for making impression in cleft lip and palate patient. Various positions such as facedown, upright, and even upside-down positions have been found in the literature for Cleft palate patient while making impression, to prevent the airway obstruction. ${ }^{9,10}$

\section{Primary Impression}

The preliminary impression was made without any premedication or anesthesia. As stock impression trays are mainly used for initial impressions in but these trays were not appropriate for the oral cavity of infant. A teaspoon which was sterilized was used to take the impression because spoon tray is cost effective, easily accessible appliances which prevents flow of impression material to the posterior airway region and provides more controlled impression technique, furthermore metal spoon tray can be sterilised easily, thus preventing any risk of cross infection ${ }^{11}$. In our study, a small piece of softened greenstick compound i.e. low fusing compound (DPITM Dental Products of India, Mumbai, India) was used to make primary impression. This primary impression material offers several benefits i.e. its low fusion temperature is readily tolerated by the child. The high rigidity of the material allows close adaptation with little chance of breakage ${ }^{12}$ (Fig. 2). It was followed by beading and boxing in order to maintain the proper borders (Fig. 3).

\section{Master Cast}

The obtained impression was poured with type III dental stone, which in turn was then lubricated with separating media (Fig. 4).

\section{Feeding Plate (FP)}

A 19 gauge wire was then bent into an omega shape and was embedded in the acrylic plate and it was prepared with clear acrylic resin and monomer by sprinkle on method. This resin was used because of its easily available, good strength and can be made with very thin margin. It was finished properly and was also polished to avoid impingement to soft tissue $>$ (Fig. 5).

\section{Delivery}

During this appointment, the feeding plate was carefully fitted in the oral cavity of infant. Early attention was given to the retention of the plate. Care was also taken to prevent the extensions of plate from impinging adjacent soft tissues (Fig. 6).

Parents were instructed about the insertion and removal of the plate and its regular maintenance and to use the plate as much as possible. The patient was recalled 
for any adjustments a week after delivery of the appliance. The oral cavity of infant was examined for any possible ulcerations or

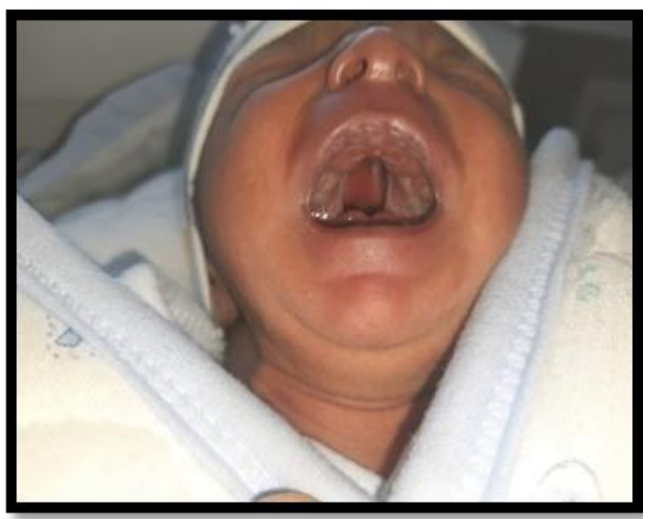

Figure: 1

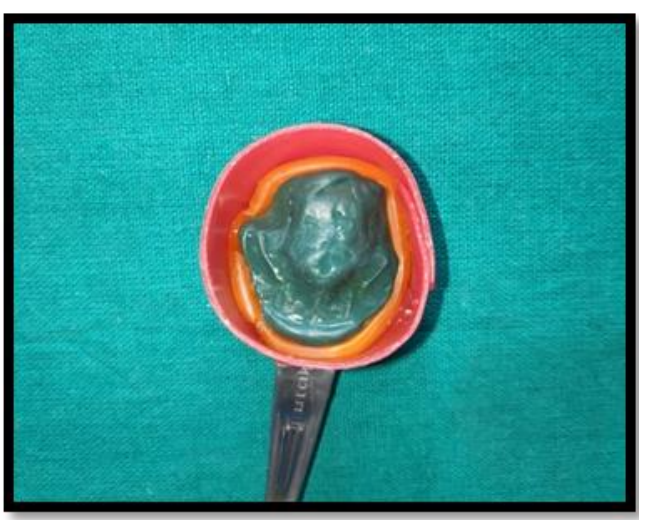

Figure: 3

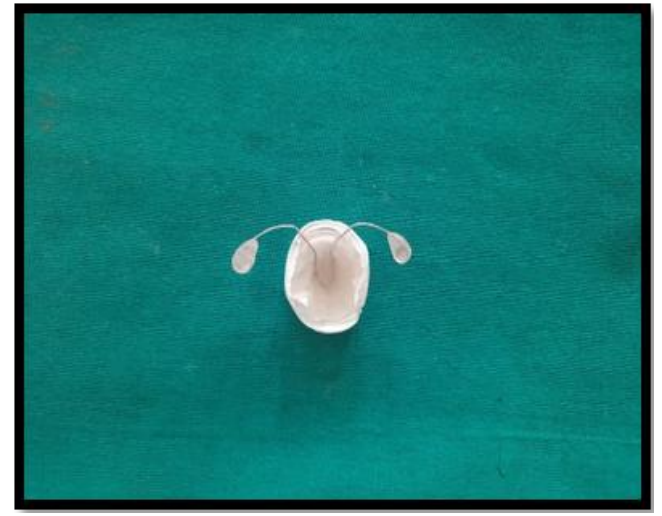

Figure: 5

\section{DISCUSSION}

There is a sense of traumatization within parents when their child is born with an orofacial cleft as there is an increased financial, social impacts before the primary treatment completion. The problems in coping are more in families with children having cleft lip and palate when compared to families with isolated cleft palate ${ }^{13}$. The present line of treatment involves a soreness. Furthermore oral hygiene and feeding instructions were reinforced.

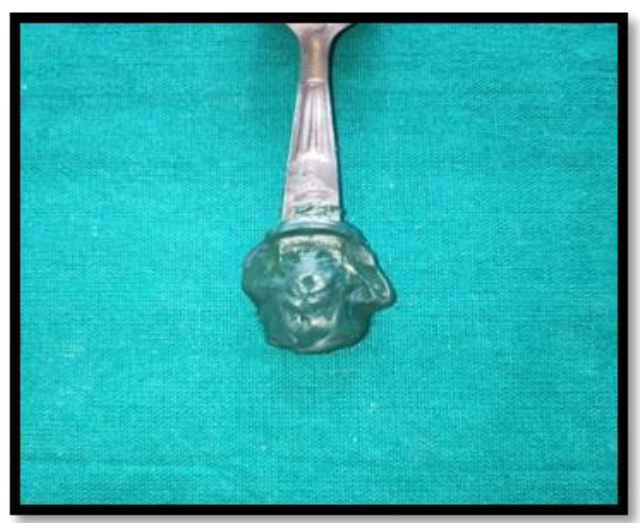

Figure: 2

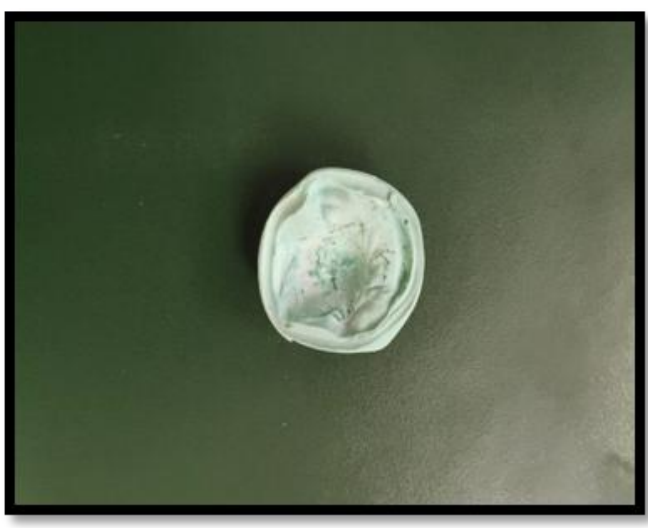

Figure: 4

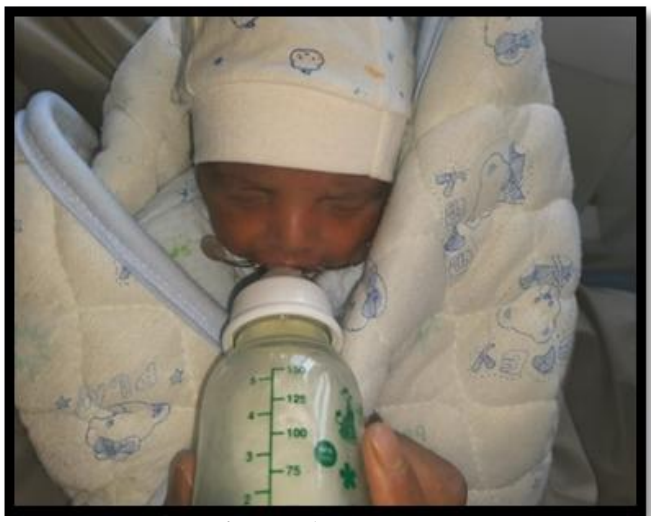

Figure: 6

reparative surgery within the first year of life. At this point of time the body weight varies between 5 and $10 \mathrm{~kg}$ and the whole blood volume between 400 and $700 \mathrm{ml}$. According to Fillies et al there was a direct relationship between decreased body weight and complications in surgery ${ }^{14}$. Infants with a cleft lip and palate have difficulty in eating, swallowing which may lead to failure to thrive. There is a decreased ability 
for the patient to create negative pressure due to oronasal communication which in turn hampers the suckling. To overcome the infant presses the nipple between the hard palate and tongue, but this mechanism is also ineffective in case of wide cleft. Nasal regurgitation and choking are other common complications $^{2}$. Early rehabilitation is a mandatory as nonsyndromic clefts also affect the quality of life in school-age children which in turn affects their social role. Thus an early intervention by conservative means should be carried out to decrease complications by increasing body weight and thereby decreasing risk of complications during surgery ${ }^{8}$. Fabrication of the feeding plate is a challenge due to variation in anatomy of cleft, lack of cooperation, size of oral cavity, and also the chances of the infant to aspirate while impression making. Thus, proper selection of impression material is necessary to reproduce exact surface details and also can be easily inserted and removed from the oral cavity, furthermore proper position of the infant is also mandatory during impression making.

\section{CONCLUSION}

The feeding plate overcomes the various problems which are associated during the normal growth and development of a cleft patient and thus should be advocated as early as possible soon after birth. It plays as an important tool in feeding, development of palatal shelves, oral-facial development, prevention of tongue distortion, nasal regurgitation and nasal septum irritation, and avoiding ear infections. Furthermore it also prevents the expansion of anterior part of the maxilla, which helps the surgeon in future to provide proper reconstructive treatment. Unnecessary, unproductive, and unproven interventions, whether speech therapy, orthodontic or prosthetic treatment or surgical procedures should be avoided as they exhaust the patient, family, and health care system, produce unfulfilled expectations, and often introduce secondary deformities.

\section{Acknowledgement: None}

Conflict of Interest: None

\section{Source of Funding: None}

\section{REFERENCES}

1. Slayton RL, Williams L, Murray J, Wheeler JJ, Lidral AC, Nishimura CJ. (2003). Genetic Association Studies of Cleft Lip and/or Palate with Hypodontia Outside the Cleft Region. Cleft Palate-Craniofac J, 40, 274-279.

2. Narendra R, Sashi Puma CR, Reddy SD, SN, Reddy SP, Prasad RB. Feeding obturator-A presurgical prosthetic aid for infants with cleft lip and palate-clinical report. Ann Essence Dent, 2013, 5(2):1-6.

3. Lodaya R, Dave A, Kunte S, Shah R. A feeding appliance for a 2 day old neonate with cleft lip and palate: a case report. Int $\mathbf{J}$ Oral Health Med Res. 2017;3(6):86-9.

4. Cooper ME, Stone RA, Liu Y, Hu DN, Melnick M, Marazita ML. Descriptive epidemiology of nonsyndromic cleft lip with or without cleft palate in Shanghai, China, from1980 to 1989. Cleft Palate Craniofac J 2000;37(3):274-280

5. Murray JC. Gene/environment causes of cleft lip and/or palate. Clin Genet 2002;61 (4):248-256

6. Ghonmode SW, Kalaskar AR, Kalaskar RR, Chole R, Bhushan P, Ali FM. Vista of cleft lip and palate in India. Evolution of Medical and Dental Sciences. 2012;1(6):1102-1111

7. Watkins SE, Meyer RE, Strauss RP, Aylsworth AS. Classification, epidemiology, and genetics of orofacial clefts. Clin Plast Surg 2014;41(2):149-163

8. Chandna P, Adlakha VK, Singh N. Feeding obturator appliance for an infant with cleft lip and palate. J Indian Soc Pedod Prev Dent 2011;29(1):71-73

9. Ravichandra KS, Vijayaprasad KE, Vasa AA, Suzan S. A new technique of impression making for an obturator in cleft lip and palate patient. J Indian Soc Pedod Prev Dent 2010;28(4): 311-314

10. Muthu MS. Management of an infant with cleft lip and palate with phocomelia in dental practice. J Indian Soc Pedod Prev Dent 2000;18(4):141-143 
11. Akay C, Karakis D, Yalug S. An alternative impression technique for an infant with cleft palate. Int Dent Res. 2015 Aug 1;5(2):3841.

12. Pani SC, Hegde A. Impressions in cleft lip and palate-A novel two stage technique. Journal of Clinical Pediatric Dentistry. 2008 Dec 1;33(2):93-6.

13. Kramer FJ, Baethge C, Sinikovic B, Schliephake H. An analysis of quality of life in 130 families having small children with cleft lip/palate using the impact on family scale. Int J Oral Maxillofac Surg 2007; 36:1146-52.

14. Fillies T, Homann C, Meyer U, Reich A, Joos U, Werkmeister R. Perioperative complications in infant cleft repair. Head Face Med 2007;3:9.

How to cite this article: Hilal Ahmad Hela, Nazir S, Qazi M. Feeding appliance for an infant with cleft palate: a case report. International Journal of Science \& Healthcare Research. 2021; 6(4): 71-75. DOI: https:// doi.org/10.52403/ijshr.20211011 